\title{
The Implications of Complicated Grief for the Sleep
}

\author{
Thiago De Almeida \\ Department of Clinical Psychology, Institute of Psychology, University of Sao Paulo (IPUSP), Sao Paulo, Brazil \\ Email: thiagodealmeida@thiagodealmeida.com.br
}

How to cite this paper: De Almeida, T. (2018) The Implications of Complicated Grief for the Sleep. Open Access Library Journal, 5: e4572.

https://doi.org/10.4236/oalib.1104572

Received: April 4, 2018

Accepted: June 26, 2018

Published: June 29, 2018

Copyright (๑) 2018 by author and Open Access Library Inc.

This work is licensed under the Creative Commons Attribution International License (CC BY 4.0).

http://creativecommons.org/licenses/by/4.0/

\section{(c) (i) Open Access}

\begin{abstract}
Complicated grief is a situation in which the individual, faced with a loss, does not present adaptive responses in dealing with this stimulus. This study aimed to understand how Complicated Grief may be a factor that may interfere in the sleep process, seeking possible relationships between these two themes. Thus, a review of the literature dealing with complicated grief and the sleep process has been done. It can be observed in cases of Complicated Grief, individuals tended to present problems related to sleep, either alterations in the amount of sleeping hours or greater difficulty in getting to sleep. Further researches are needed to relate Complicated Grief to the sleep process since those are two aspects that can be related.
\end{abstract}

\section{Subject Areas}

Psychology

\section{Keywords}

Sleep, Grief, Complicated Grief, Love, Loving Relationship

\section{Introduction}

Is grief the price of love? Maybe it is the "cost of commitment", as Colin Murray Parkes entitles the opening chapter of his seminal work Bereavement. Studies of Grief in Adult Life [1]. But, the experience of mourning is fundamentally human. As close attachment relationships (several times be in love not means be loved reciprocally) are a near-universal human experience, so grief following the permanent loss of such a relationship is a normal part of being human. When it comes to death and mourning, it is natural to think of both as meaning that someone who departs for another plane, and this is the outcome of the whole living being. According to [2], the experience of the death of the other can be 
understood by the subject as death itself and the breaking of established bonds. Faced with this, death is also seen as the loss of the connection between one person and another, not only as an organic process, thus, the breaking of a loving relationship, so bonds and affections are broken down, consists in a death and of course grief, process of reorganization to grief. Consequently, grief is a complex process physically and psychologically not only a state. It takes time to work through. Grief is a natural response to a significant loss.

It is denominated grief the consequence to a significant loss in the life of a person and it configures like the process of reestablishment and emotional, cognitive and behavioral adaptation of the person in grief. It is a painful and essentially lonely process. According to [3] the process of grief represents the experiential state that the person suffers after becoming aware of the loss, being a global term to describe the wide range of emotions, experiences, changes and conditions that occur because of the loss.

We can define grief as a natural process that consists of a set of normal and expected reactions before the breakup of significant links, usually by the death of another being, and whose function is to provide itself reconstruction, and at the same time, enable the process of adapting to changes [4] [5] [6] point to the process of loss as something totally subjective, which each individual experiences in a certain way. It is up to the professional in the field of mental health, especially for psychologists, to identify such aspects, perceiving the way the individual experiences this process, seeking to work meaningfully with their meanings and difficulties. [7] emphasizes the importance of inter subjectivity as an important element for understanding the grieving process, and this author reports an impossibility of overcoming those losses.

[4] argues that grief is usually come with symptoms such as sadness, depression, lack of interest in the outside world, difficulty in drafting feelings, inhibition of the activities, decreased self-esteem, and the presence of guilt, self-pity and punishment that are considerate bereavement states. [8] points to a possible negativism of the individual in the process of grief. [9] emphasize that in the current scenario many use digital resources to cope with grief, being a place where there is social support, and an environment used to reflect on the relationship that one had with someone who was lacking. There is a wide variety in the expression of feelings, and a space to make private feelings become public. We can see that these manifestations that happen through the Internet can be abroad field for new researchers to explore.

The grief loss can mean also the losing an image that was have of that other person, not having the possibility of a new contact. This loss can cause us to allude to other situations where this also happened. The loss of a loved one and your consequent grief is also one of the most intensely painful of all human experiences [10]. But, the bereavement is a highly disruptive experience that is usually followed by a painful but time-limited period of acute grief that often elicits powerful feelings of anxiety, hopelessness, and sorrow [11]. According to [4] 
the greater the attachment to the lost object (which can be a person, animals, stage of life, social status etc.), greater the suffering of grief. In other words, the experience of loss is an unique experience and depends on the meanings of the mourner. Also, according to this author, the greater the loss involved, the greater the mobilization of energy required for shutdown and overcoming the loss.

The intensity of grief and duration of each stage in their preparation, according to the [12] are very particular and will depend on several factors related to each person. But a minority of individuals experience a prolonged and impairing complicated grief, an identifiable syndrome that differs from usual grief, major depression, and other diagnostic entities like as characterized in the [13].

Bereavement is listed in the DSM IV-TR as a DSM V code for additional conditions that may be a focus of clinical attention. The criteria recommend not diagnosing depression related to bereavement until 2 months have passed from the loss but recognize certain symptoms which are not characteristic of a normal grief reaction (including guilt, suicidality, worthlessness, psychomotor retardation, continued severe functional impairment, and persistent hallucinations).

Underlying processes guiding symptoms are not well understood for either usual or Complicated Grief (CG). Thus, for clarification, according to [14] the term bereavement refers to a person's reaction to a loss by death. Grief is the emotional and/or psychological reaction to a significant loss, not necessarily limited to loss by death. Mourning is the social expression of grief or bereavement and is often influenced by religious beliefs and cultural custom. Complicated Grief, with symptoms such as preoccupation with the deceased, searching, and yearning, is a potential complication of bereavement related to trauma and separation distress. However, the situation of Complicated Grief occurs when recurrent intrusive pangs of grief, persistent yearning and longing for the deceased, intrusive thoughts of death, and avoidance of reminders of the lost individual can be observed [15]-[21].

In this way, in affective-sexual terms, it is considered Complicated Grief (CG), when the functional capacity of the individual is concerned, in such a way that it makes it impossible to resume normal activities, previous to the romantic loss, which can alter some biological mechanisms, such as the circadian clock and sleep, among other physiological rhythms [22] [23]. An article by John Wilson, "The Nature of Complicated Grief," can be utilized to differentiate complicated grief from normal grief. In this article are some factors that are known to put a griever at increased risk for CG: 1) Death of a child or spouse; 2) Lack of family or social support 3) Issues around how they found out about the death 4) History of anxiety or depression before the loss; 5) The death was violent or traumatic; 6) Long term marriage with a strong dependence on the lost spouse.

Thus, it is necessary to bear in mind that grief alone is already a high-risk factor for physical and mental health and may persist for extended periods of time after loss, resulting in a process of Complicated Grief [24] [25] [26] [27]. Although most individuals can cope with the process of grief and without additional complications [28] [29], others are unable to do so successfully [30] [31]; 
[32] [33] [34]. Although authors such as [35] indicate that bereaved individuals are at greater risk of mental and physical disorders, and the prevention and treatment of Complicated Grief is indicated for such cases, academic literature is incipient both in studying and in dealing with situations involving grief and complicated grief, especially about loss of love.

[36] say that situations as the bereavement can change any biological mechanisms, as the including circadian clock and the sleep and your rhythms [23]. Complementarily, the authors [37] will point out that:

Sleep is actively generated from two mechanisms that regulate the sleep-wake cycle: 1) homeostatic impulse by sleep, i.e. substances that promote sleep; 2) the circadian cycle, regulated by the suprachiasmatic nucleus of the hypothalamus, which promotes arousal. The homeostatic factor refers to increased sleepiness after long periods of wakefulness by the accumulation of adenosine, where as the circadian factor refers to variations in wakefulness and physiological sleep (time, duration and other characteristics) that change cyclically during the day (p. 58).

Although most individuals can normatively address the grieving process without additional complications, others are unable to do so successfully, thus presenting difficulties of emotional regulation to overcome this traumatic event [32]. [38] defines Emotional Regulation as a combination of psychological, physiological, neurochemical, social and behavioral processes, that is, all the intrinsic and extrinsic processes, conscious and unconscious that affect the components of emotion. Complementarily, [39] point out that the process of emotional regulation concerns the activation of processes by which individuals influence what emotions they will have, when they will have them and how they will experience and express those emotions. This process may lead to an increase or decrease of both positive and negative emotions, and may be automatic or controlled, conscious or unconscious [40]. Emotional Regulation can occur in many ways. Thus, one of the most common alternatives is deliberate self-regulation, using conscious cognitive processes. However, it is also possible for the subject to regulate their emotions autonomously, even though this form occurs less frequently. For [41], emotional regulation has a fundamental role in the life of the individual in obtaining quality of life, and more studies are necessary to address this issue due to its importance.

According to [42], these emotional competences can help young people in other contexts such as work, helping in the development of new skills and learning. [43] discuss emotional regulation as the subject's ability to adapt to the circumstances of the moment by modulating his or her emotions. However [44], defend a multidimensional definition, since Emotional Regulation encompasses, in addition to the modulation of emotional activation, the awareness, understanding and acceptance of emotions, as well as the ability to control behaviors impulsive, appropriate and flexible use of emotional regulation strategies to achieve individual goals and situational requirements. Thus, for these authors, 
the inexistence of certain or all aptitudes may be indicative of difficulties in emotional regulation or emotional dysregulation. So, it is concluded that, there are several models of Emotional Regulation that allow different strategies, whether adaptive or maladaptive to overcome certain human difficulties.

There are still few studies dealing with loss that does not involve the question of death, at which point it becomes important to analyze the loss of love and its implications, especially for the issue of sleep. Studies on sleep, since the 1970s, have pointed out that the sleep is often altered after major life events or life transitions, particularly those that are mood disturbing [45] [46]. Sleep, particularly sleep, may remain altered for prolonged periods after excessively negative or protracted stressors, as seen in the case of posttraumatic stress disorder [47].

But is which the price of the love of Bereavement and the Complicated Grief to the Adult Life? This paper is a literature review about this subject pointing one of the consequences of Complicated Grief (CG) especially for sleep criteria.

\section{Sleep functions}

By nature, man is a being of many wants and needs. Abraham Maslow was a psychologist of great importance because of his study of human needs. According to Maslow, these needs are organized and available in a hierarchy of prominence composed of: physiological needs, safety, self-fulfillment, social needs, status needs, and esteem. Being the physiological necessities essential to the organism, such as food, water, sleep among others. It can be concluded that as a basic necessity, sleep is fundamental in the life of all of us [48].

Normally, all living beings feels the need to sleep. Normally, we spent about one third of our life sleeping. The sleep is essential for the well functioning of our cognitive abilities. Whatever part of day sometime we reserve to sleep, being long or short. But after all, sleep is produced by exactly what? While there is a completely scientific justification, which is the importance for sleep? Why do we have to disconnect one third of our lives in this reality? What if we did could not sleep? The sleep, almost all mammals or birds can be could sleep br considered an "useless" accessory from the point of view of the survival of organisms?

Everything indicates that the sleep is very important and the conservation of sleep across all animal species suggests that sleep serves a vital function. In many circumstances sleeping may be a less dangerous choice than roaming around, wasting energy and exposing oneself to predators. Also, if sleep is just one out of a repertoire of available behaviors that is useful without being essential, it is easier to explain why sleep duration varies so much across species [49] [50] [51]. Even so, sleep functions are not restricted only to preservation of a given species, but are related to a broad sort of aspects. According to many authors, the sleep is useful to:

1) Preparation for the next day: Sleep is useful to prepare the body for the next period of wakefulness. For this reason sleep would be the main period of anabolism;

2) Repair and replacement energy: Sleep would be the time to restore the 
energetic stocks, depending on spending the previous day. For this reason, we would sleep over the more active we have been yesterday;

3) Energy balance and metabolic balance: Integrates the first and the second theories and adds a few things. It seems that during the day the body accumulates metabolites that, when they reach a certain level, indicates the sleep. Some of them metabolites like as serotonin and adenosine;

4) Feasibility synaptic homeostasis: Sleep serves to restore synaptic viability after long-term use. According to this theory the ability synaptic saturable and requires a time of quiescence to resume activity. According to this theory, it is possible to exist be possible "local" sleeps. That is, only a part of the brain sleep, which would depending on demand and sleep pressure.

5) Cognition: Sleep, particularly REM would be responsible for the consolidation of multiple cognitive processes, especially the long-term memory;

6) Protection of the species. The sleep could adapt the animals of a given environment to its ecological position. In this case, this hypothesis does not explain the importance of sleep, but the adaptive importance of adaptive modulative sleep patterns modular. According to this theory, the sleep of predators always will focus on a single period, with episodes quite deep episodes of sleep and in a very specific period. The sleep of preyed is more superficial and fragmented, to be always alert and respond to any danger signal.

\section{Method}

Taking into account that the objective of this work was to identify in the academic literature contents related to the guiding question of this research, which was to identify as a process of amorous grief may be a factor that predisposes to problems related to sleep, a computerized search of the literature, using Bvs Psi indexer data, without date limit until the year 2017, with the terms/keywords: "Complicated Grief", "sleep problems" and "complicated sleep and grief" and "amorous grief". The Virtual Health Library-Psychology Brazil or simply (BVS-Psi Brazil) is a reference in Latin America and Brazil in scientific information in quality Psychology, which differs from the set of Internet information sources by complying with selection and quality control criteria, with diverse databases and some with more than 30 years.

This research provided a total of 96 papers. Of these, 83 were excluded from the topic proposed in this study because they refer to literary works, publications as books that are not considered in this study, where the search was restricted only to scientific articles having as descriptors at least two of the searched terms, resulting in 9 references. Of these, thirteen references, all referred to the topic proposed by the article, remembering that for the discussion of the data were included additional references that corroborate directly with the sieves of this study. He took advantage of the intersections between the categories to describe them as categories. We will now comment in detail on our findings. 


\section{Results}

Complicated grief is usually chronic and incapacitating, sharing some symptoms with Major Depressive Disorder (MDD) and Posttraumatic Stress Disorder (PTSD), but the specific constellation of symptoms is unique to this disorder. It is necessary to have an explanation to the Major Depressive Disorder and Posttraumatic Stress Disorder.

In DSM-V, there were two changes relevant to the understanding of the engagement. The first consists in the withdrawal of grief reactions as a criterion of exclusion for the diagnosis of depression and the second; it is included in a session covering what has been termed as "Persistent Complex Bereavement Disorder". About that point, bereavement needs to be better understood, because it still borderline aspect between which we can consider as "normal" and "pathological". In any case, the diagnosis of complicated mourning extends, in DSM-5, for one year of persistent symptoms adults and six months among children, with two months for the diagnosis of depression.

Complicated grief and, Major Depressive Disorder (MDD) and persistent depressive disorder (Dysthymia) share sadness, weeping, and suicidal thinking. While major depressive disorder and persistent disorder may share depressed mood with persistent complex disorder, the latter is characterized by a focus on loss post-traumatic stress disorder. Individuals who experience grief because of traumatic death may develop both posttraumatic stress disorder (PTSD) and persistent complex mourning disorder. Both conditions can involve intrusive thoughts and avoidance. While intrusions in PTSD focus on the traumatic event, intrusive memories in persistent complex mourning disorder are focused and the content of these thoughts are related to aspects of the relationship with the deceased, including positive aspects of the relationship and distress suffering.

1) The grief experience.

According to [5] is very common for people who have suffered the experience of loss entering into a process of emotional breakdown which can often cause a concussion on mental health and hinder the vital process of development like as lack of sleep. These losses are not necessarily associated with death experience. Authors as [52] [53] and [5], highlight other experiences that involve loss, such as separations between living persons, as family separations, separation of friends, marital health loss arising from the installation of a disease (transient, and especially, chronic diseases), situations loss material possessions loss, between among other possibilities.

Poor sleep quality and insomnia complaints are common in bereaved individuals [54] [55] [56] [57]. In a recent study, we have it was found that clinically significant sleep disturbance also characterizes nearly all CG patients [58]. Sleep disturbance, however, is not currently listed as a formal characteristic of CG and is not directly addressed in CG interventions.

Complicated grief (CG) is a recently redefined condition [59]; Authors as [19] [60] [61] estimated to affect $10 \%$ to $20 \%$ of bereaved individuals. CG is usually 
chronic and disabling, sharing some symptoms with Major Depressive Disorder (MDD) and Posttraumatic Stress Disorder (PTSD), but the specific constellation of symptoms is unique to this disorder [21] [59]. Core CG symptoms include a sense of disbelief regarding the death; anger and bitterness over the death; recurrent pangs of painful emotions with intense yearning and longing for the deceased; and preoccupation with thoughts of the loved one, often including distressing intrusive thoughts related to the death. More generally, poor sleep quality is a risk factor for psychiatric morbidity and mortality [62] [63]. Sleep quality has not been directly evaluated in CG in relation to the presence or absence of comorbid depression or PTSD.

2) Loving Breakup as Grief: Considerations about sleep interference.

Men, during his lifetime, will experience various experiences, including losses and separations. With these losses and separations, the human being enters into a process called grief. As previously stated, it is a painful and solitary process, but it aims at emotional, cognitive and behavioral recovery.

Grief is not only restricted to a loss due to natural death, it also presents as a consequence of any deprivation, be it marital ruptures, city/work change, friendship breaks, among others. It is then understood as an inherent process to the human being. However, society usually configures grief solely as the process of definitive separation, that is, death.

Love relationships are usually grounded and oriented as a sense of belonging, ultimate desire for closeness and interdependence. The affective/loving practice is directly associated with representations that the subjects learn from the relationship with their parents during childhood, thus affective language is learned in the family system [64]. If this first experience of love in childhood is satisfactory, then the subject will learn and put into practice empathy, as well as develop confidence and consequently maturity for their next personal relationships. However, as described by [64]:

In summary, some people have difficulties in dealing with ruptures of love relationships, possibly due to the fact that, in interpersonal experience, they assimilated negative representations about themselves, resulting from experiences of conditional love (or even absence of love) of their criterion people (in this case, parents or caregivers). The assimilation of these negative representations can end up generating depressive states and undermine the subject's self-esteem, triggering psychological mechanisms (translated by postures, by ways of being-in-the-world) that seek to compensate for the idea of a loss of self-esteem (p. 613).

Even with the high rates of marital separation, literature also does not see it as a loss process to be elaborated, nor does it address the feelings and thoughts of the separated person, limiting only the consequences of that separation [65]. If it is a matter of grief for natural death and mourning due to the breakup of the love relationship, it can be seen that grief for love breakup is more painful than grief for death, for the mourner "buries" his lifemate, the idealized dreams and 
expectations are gone.

The process of grief leads to various forms of manifestations ranging from psychological, social, behavioral, affective and physiological with varying duration and proportion [66]. Complementing this idea, according to [67] grief presents various feelings such as anxiety, guilt, anger, hostility, loneliness, frustration, self-recrimination, yearning. Physical symptoms of loss of appetite, sleep disturbances, loss of energy and decreased immune system. Agitation, fatigue, crying, difficulty in relationships, ambivalence, confusion, forgetfulness, feeling of presence of the deceased, slowness of thought and difficulty concentrating are also possible symptoms of grief.

Also, about the sleep interferences can be cited: difficulty getting off to sleep because of intrusive thoughts, restless and disturbed sleep, feeling tired and fatigued, dreams and nightmares about what happened and unpleasant dreams of other frightening thoughts. And what is the importance of these symptoms to the question of complicated mourning? As seen, the quantity and quality of sleep are terribly impaired in traumatic situations such as those involving a diagnosis of complicated grief, especially of a loving nature, since this homeostatic balance is considerably altered. In this sense, improvements in the quality and amount of sleep reappear can be an important reference that can be used as a parameter to verify the resilience of the person in regard to overcoming their loss.

Pain from grief has a validity period to end and its intensity is proportional to the level of attachment that the subject has established with that person or condition. The study of mourning as a process is interesting because several aspects, both individual, social and cultural, as well as personality characteristics of the mourner contribute to their understanding. It is a comorbid process.

For many people, especially in contemporary Western society, not to manifest suffering for love can be considered a betrayal of being loved, in the sense that there is an interpretation that this person was not loved and valued enough by those who should suffer for their absence. [68] shows that there is a kind of loving glamor in loving suffering and that, since ancient times, people have been suffering and being overwhelmed by romantic ruptures. Consequently, realize how much the suffering of love also has its space guaranteed in our romantic western culture.

Regarding the symptoms and feelings previously mentioned, it is important to emphasize that caution is necessary in relation to the diagnosis of depression of the bereaved person. Sadness is not depression. Reactive depression is expected, but intensity and duration, if exacerbated, may indicate pathology. In accordance with what was quoted, [69] complement:

A large number of mourners may present somatic pictures and serious illnesses after the loss, and may constitute a reactive depression or even a more severe picture. The death of a loved one is very stressful for humans. It is known that stressful events are in memory, and can be used as very vivid mental images. 
The depressed state, the stress and anxiety generated by the mourning process in possible comorbidity with depression, provoke physical and psychological tension, leads to fatigue and consequently to sleep disturbances. Taking into account that sleep is an essential determinant of the body's circadian patterns, and its deprivation or alteration disturbs the time of endocrine release and neurotransmitters, it can be observed that the sleep of people who experience mourning situations tends to be of low efficiency. They report that they rarely or never go into deep sleep, which is associated with a sense of renewal and rest. In this way, it can be inferred that during the mourning process, in the most severe cases, sleep can not be considered a restorative and energy repository instrument. However, while this sleep during the depressed state can bring the person down, the lack of chronic sleep can be triggering depression [70].

\section{3) Final considerations}

Generally, this study aimed to understand how Complicated Grief may be a factor that may interfere in the sleep process, seeking possible relationships between these two themes. Although we do not know what sleep is, we know it is important, because we know how bad it is to be without it. Therefore, if a grieving person does not sleep, this is the problem. Not sleeping is the problem. The problem is the lack of sleep. Further research can be conducted questioning the relationship between sleep and mourning, and perhaps characterizing it as a criterion in order to differentiate the normal grief of from Complicated Grief. Because as sleep is a modifiable behavior, the study of sleep in individuals with CG may yield important refinements and more effective prevention and therapeutic efforts.

Given the considerations previously made, can understand that sleep is a fundamental process for human functioning. Several organic processes need sleep to happen, and a person who does not sleep can have their health severely affected due to this condition.

During complicated mourning, sleep may suffer changes, the individual almost always reports a greater difficulty sleeping in the period in which he goes through a complicated mourning. However, it is good to know if there are any neurobiological or physiological correlates, and this would be achieved with polysomnography. Some questions that can be raised can be: Is there a decrease in total sleep time, the amount of slow-wave sleep, increased sleep latency or REM, sleep fragmentation? This is particularly important because of a disorder called insomnia of poor perception or psychophysiological insomnia. In this case, the person reports insomnia in the interviews and questionnaires, although the polysomnographic examination demonstrates a perfectly normal and enviable sleep. Therefore, in that case the person for some reason usually related to anxiety depression and guilt, do not notice that they are sleeping normally. Bereaved people can fit that description. Studies that focus on these themes are necessary, and are capable of exploring the questions left in this manuscript, whose main limitation there was not an opportunity to perform, in addition to this bib- 
liographic survey for the present article, an experimental research that verified the hypothesis of how much complicated mourning may be involved with sleep abnormalities in quantitative terms and in qualitative terms. Further studies are needed to relate Complicated Grief to the sleep process since these are two aspects that can be related. In this sense, this study that focused on raising the intersection of these research themes can be considered a pioneering study from which researchers and clinicians can take it as a basis to base their daily and experimental clinical observations.

\section{Acknowledgements}

Acknowledgements to Bruno Martins Lima, industrial engineer for the revision of manuscript.

\section{References}

[1] Parkes, C.M. (1986) Bereavement: Studies of Grief in Adult Life. Pelican, Harmondswortii and Tavistock, London,

[2] Caterina, M.C. (2008) O luto: perdas e rompimento de vínculos. APVP-Associação Psicanalítica do Vale do Paraíba. (Módulo 28).

[3] Sanders, C. (1999) Grief: The Mourning after: Dealing with Adult Bereavement. Jonh Wiley \& Sons, New York.

[4] Bowlby, J. (2004) Apego e perda: separação: angústia e raiva. Vol. 2, Martins Fontes, São Paulo.

[5] Parkes, C.M. (1998) Luto: estudos sobre a perda na vida adulta (M. H. P. Franco, Trad). Summus, São Paulo,

[6] Lemos, L.S. and Cunha, A.C.B. (2015) Concepções sobre morte e luto: experiencia feminina sobre a perda gestacional. Psicologia: ciência e profissão, 35, 1120-1138.

[7] Freitas, J.L. (2013). Luto e fenomenologia: uma proposta compreensiva. Revista da Abordagem Gestáltica, 19, 97-105. https://doi.org/10.18065/RAG.2013v19n1.12

[8] Schmidt, E. (2013) Melancolia, depressão e suas narrativas. Revista Latinoamericana de Psicopatologia Fundamental, 16, 88-99. https://doi.org/10.1590/S1415-47142013000100007

[9] Bousso, R.S., Ramos, D., Frizzo, H.C.F., Santos, M.R. and Bousso, F. (2014) Facebook: um novo lócus para a manifestação de uma perda significativa. Psicologia USP, 25, 172-179. https://doi.org/10.1590/0103-656420130022

[10] Boelen, P.A. (2010) A Sense of "Unrealness" about the Death of a Loved-One: An Exploratory Study of Its Role in Emotional Complications among Bereaved Individuals. Applied Cognitive Psychology, 24, 238-251. https://doi.org/10.1002/acp.1557

[11] Bonanno, G.A. and Kaltman, S. (1999) Toward an Integrative Perspective on Bereavement. Psychological Bulletin, 125, 760-776. https://doi.org/10.1037/0033-2909.125.6.760

[12] Ross, K.E. (1992) Sobre a morte e o morrer. Martins Fontes, São Paulo.

[13] American Psychiatric Association (2013) Diagnostic and Statistical Manual of Mental Disorders (DSM-V). 5th Edition, American Psychiatric Association, Arlington.

[14] Hensley, P.L. (2006) Treatment of Bereavement-Related Depression and Traumatic 
Grief. Journal of Affective Disorders, 92, 117-124.

https://doi.org/10.1016/j.jad.2005.12.041

[15] Horowitz, M.J., Siegel, B., Holen, A., Bonanno, G.A., Milbrath, C. and Stinson, C.H. (1997) Diagnostic Criteria for Complicated Grief Disorder. American Journal of Psychiatry, 154, 904-910. https://doi.org/10.1176/ajp.154.7.904

[16] Lobb, E.A., Kristjanson, L.J., Aoun, S.M., Monterosso, L., Halkett, G.K.B. and Davies, A. (2010) Predictors of Complicated Grief: A Systematic Review of Empirical Studies. Death Studies, 34, 673. https://doi.org/10.1080/07481187.2010.496686

[17] Maccallum, F. and Bryant, R.A. (2010) Attentional Bias in Complicated Grief. Journal of Affective Disorders, 125, 316-322. https://doi.org/10.1016/j.jad.2010.01.070

[18] Maccallum, F. and Bryant, R.A. (2010) Impaired Autobiographical Memory in Complicated Grief. Behaviour Research and Therapy, 48, 328-334. https://doi.org/10.1016/j.brat.2009.12.006

[19] Prigerson, H.G., Frank, E., Kasl, S.V., Reynolds, C.F. III, Anderson, B., Zubenko, G.S., Kupfer, D.J., et al. (1995) Complicated Grief and Bereavement-Related Depression as Distinct Disorders: Preliminary Empirical Validation in Elderly Bereaved Spouses. The American Journal of Psychiatry, 152, 22-30. https://doi.org/10.1176/ajp.152.1.22

[20] Boelen, P.A., Van den Hout, M.A. and Van den Bout, J. (2006) A Cognitive-Behavioral Conceptualization of Complicated Grief. Clinical Psychology: Science and Practice, 13, 109-128. https://doi.org/10.1111/j.1468-2850.2006.00013.x

[21] Boelen, P.A., Van den Bout, J. and de Keijser, J. (2003) Traumatic Grief as a Disorder Distinct from Bereavement-Related Depression and Anxiety: A Replication Study with Bereaved Mental Health Care Patients. American Journal of Psychiatry, 160, 1339-1341. https://doi.org/10.1176/appi.ajp.160.7.1339

[22] Lotterman, J.H., Bonanno, G.A. and Galatzer-Levy, I. (2014) The Heterogeneity of Long-Term Grief Reactions. Journal of Affective Disorders, 167, 12-19. https://doi.org/10.1016/j.jad.2014.05.048

[23] Reynolds, C.F. III, Hoch, C.C., Buysse, D.J., Houck, P.R., Schlernitzauer, M., Pasternak, R.E., Kupfer, D.J., et al. (1993) Sleep after Spousal Bereavement: A Study of Recovery from Stress. Biological Psychiatry, 34, 791-797. https://doi.org/10.1016/0006-3223(93)90068-O

[24] Jordan, A.H. and Litz, B.T. (2014) Prolonged Grief Disorder: Diagnostic, Assessment, and Treatment Considerations. Professional Psychology: Research and Practice, 45, 180-187. https://doi.org/10.1037/a0036836

[25] O’Connor, M.F., Allen, J.J.B. and Kaszniak, A.W. (2002) Autonomic and Emotion Regulation in Bereavement and Depression. Journal of Psychosomatic Research, 52, 183-185. https://doi.org/10.1016/S0022-3999(02)00292-1

[26] Stroebe, M., Schut, H. and Van den Bout, J. (2012) Complicated Grief: Scientific Foundations for Health Care Professionals. Routledge, New York.

[27] O’Connor, M.-F., Shear, M.K., Fox, R., Skritskaya, N., Campbell, B. and Ghesquiere, A. (2013) Catecholamine Predictors of Complicated Grief Treatment Outcomes. International Journal of Psychophysiology, 88, 349. https://doi.org/10.1016/j.ijpsycho.2012.09.014

[28] Bonanno, G.A. (2004) Loss, Trauma, and Human Resilience: Have We Underestimated the Human Capacity to Thrive after Extremely Aversive Events? American Psychologist, 59, 20-28. https://doi.org/10.1037/0003-066X.59.1.20 
[29] Kersting, A., Brähler, E., Glaesmer, H. and Wagner, B. (2011) Prevalence of Complicated Grief in a Representative Population-Based Sample. Journal of Affective Disorders, 131, 339-343. https://doi.org/10.1016/j.jad.2010.11.032

[30] Boelen, P.A. and Prigerson, H.G. (2012) Commentary on the Inclusion of Persistent Complex Bereavement-Related Disorder in DSM-5. Death Studies, 36, 771-794. https://doi.org/10.1080/07481187.2012.706982

[31] Bui, E., Nadal-Vicens, M. and Simon, N.M. (2012) Pharmacological Approaches to the Treatment of Complicated Grief: Rationale and a Brief Review of the Literature. Dialogues in Clinical Neuroscience, 14, 149-157.

[32] Howarth, R. (2011) Concepts and Controversies in Grief and Loss. Journal of Mental Health Counseling, 33, 4-10. https://doi.org/10.17744/mehc.33.1.900m56162888u737

[33] Papa, A., Sewell, M.T., Garrison-Diehn, C. and Rummel, C. (2013) A Randomized Open Trial Assessing the Feasibility of Behavioral Activation for Pathological Grief Responding. Behavior Therapy, 44, 639-650. https://doi.org/10.1016/j.beth.2013.04.009

[34] Rosner, R., Lumbeck, G. and Geissner, E. (2011) Effectiveness of an Inpatient Group Therapy for Comorbid Complicated Grief Disorder. Psychotherapy Research, 21, 210-218. https://doi.org/10.1080/10503307.2010.545839

[35] Wittouck, C., Van Autreve, S., De Jaegere, E., Portzky, G. and Van Heeringen, K. (2011) The Prevention and Treatment of Complicated Grief: A Metaanalysis. Clinical Psychology Review, 31, 69-78. https://doi.org/10.1016/j.cpr.2010.09.005

[36] Shear, K. and Shair, H. (2005) Attachment, Loss, and Complicated Grief. Developmental Psychobiology, 47, 253-267. https://doi.org/10.1002/dev.20091

[37] Neves, G.S., Moura, L., Giorelli, A.S., Florido, P. and Gomes, M.M. (2013) Transtornos do sono: Visão geral. Revista Brasileira de Neurologia, 49, 57-71.

[38] Gross, J.J. (2001) Emotion Regulation in Adulthood: Timing Is Everything. Current Directions in Psychological Science, 10, 214-219. https://doi.org/10.1111/1467-8721.00152

[39] Batistoni, S.S.T., Ordonez, T.N., Silva, T.B.L., Nascimento, P.P.P., Kissaki, P.T. and Cachioni, M. (2013) Depressive Symptoms in Elderly Participants of an Open University for Elderly. Dementia e Neuropsychologia, 5, 85-92. https://doi.org/10.1590/S1980-57642011DN05020005

[40] Ehring, T., Tuschen-Caffier, B., Schnülle, J., Fischer, S. and Gross, J.J. (2010) Emotion Regulation and Vulnerability to Depression: Spontaneous versus Instructed Use of Emotion Suppression and Reappraisal. Emotion, 10, 563-572. https://doi.org/10.1037/a0019010

[41] Bueno, J.M.H., Correia, F.M.L., Abacar, M., Gomes, Y.A. and Júnior, F.S.P. (2015) Competências emocionais: Estudo de validação de um instrumento de medida. Avaliação Psicológica, 14, 153-163. https://doi.org/10.15689/ap.2015.1401.17

[42] Gondim, S.M.G., Morais, F.A. and Brantes, C. (2014) Competências socioemocionais: Fator-chave no desenvolvimento de competências para o trabalho. Revista Psicologia: Organizações e Trabalho, 14, 394-406.

[43] Bridges, L.J., Denham, S.A. and Ganiban, J.M. (2004) Definitional Issues in Emotion Regulation. Child Development, 75, 340-345. https://doi.org/10.1111/j.1467-8624.2004.00675.x

[44] Gratz, K.L. and Roemer, L. (2004) Multidimensional Assessment of Emotion Regulation and Dysregulation: Development, Factor Structure, and Initial Validation of 
the Difficulties in Emotion Regulation Scale. Journal of Psychopathology and Behavioural Assessment, 26, 41-45.

https://doi.org/10.1023/B:JOBA.0000007455.08539.94

[45] Clayton, P.J., Halikas, J.A. and Mauria, W.L. (1972) The Depression of Widowhood. The British Journal of Psychiatry, 120, 71-78. https://doi.org/10.1192/bjp.120.554.71

[46] Clayton, P.J. (1975) Weight Loss and Sleep Disturbance in Bereavemere. In: Schoenberg, B., Gerber, I., Wiener, A., Kutscher, A.H., Pert'eta, D. and Carr, A.D., Eds., Bereavement. Psychosocial as Peers, Columbia University Press, New York, 72-77.

[47] Ross, R.J., Ball, W.A., Cohen, M.E., Silver, S.M., Morrison, A.R. and Dinges, D.F. (1989) Habituation of the Startle Reflex in Posttraumatic Stress Disorder. The Journal of Neuropsychiatry and Clinical Neurosciences, 1, 305-307. https://doi.org/10.1176/jnp.1.3.305

[48] Cirelli, C. and Tononi, G. (2008) Is Sleep Essential? PLoS Biology, 6, 1605-1611. https://doi.org/10.1371/journal.pbio.0060216

[49] Campbell, S.S. and Tobler, I. (1984) Animal Sleep: A Review of Sleep Duration across Phylogeny. Neuroscience \& Biobehavioral Reviews, 8, 269-300. https://doi.org/10.1016/0149-7634(84)90054-X

[50] Capellini, I., Barton, R.A., McNamara, P., Preston, B.T. and Nunn, C.L. (2008) Phylogenetic Analysis of the Ecology and Evolution of Mammalian Sleep: A Reappraisal. Evolution, 62, 1764-1776. https://doi.org/10.1111/j.1558-5646.2008.00392.x

[51] Lesku, J.A., Roth, T.C., Rattenborg, N.C., Amlaner, C.J. and Lima, S.L. (2008) Phylogenetics and the Correlates of Mammalian Sleep: A Reappraisal. Sleep Medicine Reviews, 12, 229-244. https://doi.org/10.1016/j.smrv.2007.10.003

[52] Fonseca, J.P. (2001) Luto antecipatório: As experiências familiares diante de uma morte anunciada. Dissertação de Mestrado, Pontifícia Universidade Católica, São Paulo.

[53] Kovács, M.J. (1996) A morte em vida. In: Bromberg, M.H.P.F., Kovács, M.J., Carvalho, M.M.J. and Carvalho, V.A., Eds., Vida e morte: Laços da existência, Casa do Psicólogo, São Paulo, 11-33.

[54] Allaert, F.A. and Urbinelli, R. (2004) Sociodemographic Profile of Insomniac Patients across National Surveys. CNS Drugs, 18, 3-7. https://doi.org/10.2165/00023210-200418001-00003

[55] Hardison, H.G., Neimeyer, R.A. and Lichstein, K.L. (2005) Insomnia and Complicated Grief Symptoms in Bereaved College Students. Behavioral Sleep Medicine, 3, 99-111. https://doi.org/10.1207/s15402010bsm0302_4

[56] Parkes, C.M. (1970) The First Year of Bereavement: A Longitudinal Study of the Reaction of London Widows to the Death of Their Husbands. Psychiatry, 33, 444-467. https://doi.org/10.1080/00332747.1970.11023644

[57] Parkes, C.M. and Brown, R. (1972) Health after Bereavement: A Controlled Study of Young Boston Widows and Widowers. Psychosomatic Medicine, 34, 449-461. https://doi.org/10.1097/00006842-197209000-00008

[58] Germain, A., Caroff, K., Buysse, D.J. and Shear, M.K. (2005) Sleep Quality in Complicated Grief. Journal of Traumatic Stress, 18, 343-346. https://doi.org/10.1002/jts.20035

[59] Prigerson, H.G., Bierhals, A.J., Kasl, S.V., Reynolds, C.F. III, Shear, M.K., Newsom, J.T. and Jacobs, S. (1996) Complicated Grief as a Disorder Distinct from 
Bereavement-Related Depression and Anxiety: A Replication Study. The American Journal of Psychiatry, 153, 1484-1486. https://doi.org/10.1176/ajp.153.11.1484

[60] Jacobs, S.C. (1993) Pathologic Grief: Maladaptation to Loss. American Psychiatric, Washington DC.

[61] Middleton, W., Burnett, P., Raphael, B. and Martinek, N. (1996) The Bereavement Response: A Cluster Analysis. British Journal of Psychiatry, 169, 167-171. https://doi.org/10.1192/bjp.169.2.167

[62] Dew, M.A., Hoch, C.C., Buysse, D.J., Monk, T.H., Begley, A.E., Houck, P.R., Reynolds, C.F. III, et al. (2003) Healthy Older Adults' Sleep Predicts All-Cause Mortality at 4 to 19 Years of Follow-Up. Psychosomatic Medicine, 65, 63-73. https://doi.org/10.1097/01.PSY.0000039756.23250.7C

[63] Ford, D.E. and Kamerow, D.B. (1989) Epidemiologic Study of Sleep Disturbances and Psychiatric Disorders: An Opportunity for Prevention? Journal of the American Medical Association, 262, 1479-1484. https://doi.org/10.1001/jama.1989.03430110069030

[64] Guedes, D.D., Monteiro-Leitner, J. and Machado, K.C.R. (2008) Rompimento amoroso, depressão e autoestima: Estudo de caso. Revista Mal-estar e Subjetividade, 8, 603-643.

[65] Rangel, A.P.F.N. (2008) Amor infinito: Histórias de pais que perderam seus filhos. Vetor, São Paulo.

[66] Almeida, T. and Aguirra, D. (2013) O fim do que era para ser para sempre: O que fazer uma vez que o luto pelo rompimento da relação acabou? In: Almeida, T., Ed., Relacionamentos amorosos. $O$ antes, o durante... e o depois, Compacta, São Carlos, 417-435, Vol. 1.

[67] Worden, J.W. (1998) Terapia do Luto. Um Manual para o profissional de saúde mental. Artes Médicas, Porto Alegre.

[68] Almeida, T. (2017) O conceito de amor: Um estudo exploratório com uma amostra brasileira. Tese de Doutorado, Instituto de Psicologia, Universidade de São Paulo, São Paulo.

[69] Habekoste, A.H. and Areosa, S.C. (2011) O luto inesperado. In 4. Jornada de Pesquisa em Psicologia: desafios atuais nas práticas da psicologia, Santa Cruz do Sul, RS.

http://online.unisc.br/acadnet/anais/index.php/jornada_psicologia/article/downloa $\underline{\mathrm{d} / 10197 / 18}$

[70] Andrew, S. (2014) O demônio do meio-dia: Uma anatomia da depressão. Companhia das Letras, São Paulo. 